\title{
Proteomic differential display identifies upregulated vinculin as a possible biomarker of pancreatic cancer
}

\author{
YUFENG WANG $^{1}$, YASUHIRO KURAMITSU ${ }^{1}$, TOMIO UENO ${ }^{2}$, NOBUAKI SUZUKI ${ }^{2}$, SHIGEFUMI YOSHINO ${ }^{2}$, \\ NORIO IIZUKA ${ }^{2}$, XIULIAN ZHANG $^{3}$, JUNKO AKADA $^{1}$, MASAAKI OKA $^{2}$ and KAZUYUKI NAKAMURA ${ }^{1}$ \\ Departments of ${ }^{1}$ Biochemistry and Functional Proteomics and ${ }^{2}$ Digestive Surgery of Applied Molecular Bioscience, \\ Yamaguchi University Graduate School of Medicine, Ube, Japan; ${ }^{3}$ The Institute of Human Nutrition, \\ Medical College of Qingdao University, Qingdao, P.R. China
}

Received March 6, 2012; Accepted May 2, 2012

DOI: $10.3892 / o r .2012 .2004$

\begin{abstract}
Pancreatic cancer (PC) is characterized by rapid tumor spread, and very few patients with PC survive for more than 5 years. It is imperative to discover additional diagnostic biomarkers or specific therapeutic targets in order to improve the treatment of patients with PC. In search for useful biomarkers, we analyzed ten pairs of non-cancerous and cancer tissues from patients with PC by two-dimensional gel electrophoresis (2-DE). Nineteen protein spots showed differential expression on 2-DE gels between the cancer and non-cancerous tissues. Six upregulated protein spots were identified by liquid chromatography-tandem mass spectrometry (LC-MS/MS) as calreticulin, glutathione synthetase, stathmin, vinculin, $\alpha$-enolase and glyceraldehyde-3-phosphate dehydrogenase. Western blotting demonstrated that vinculin was predominantly expressed in the pancreatic cancer tissues compared with to non-cancerous tissues. Our findings indicate that vinculin may be a clinically useful biomarker of PC.
\end{abstract}

\section{Introduction}

Prognosis of patients with pancreatic cancer (PC) is poor because of belated diagnosis and lack of effective therapies. This disease is characterized by rapid tumor spread, and the median survival is less than 12 months with an overall 5-year survival rate of $<5 \%$ (1). It is imminent therefore to find more effective biomarkers for the diagnosis of patients with pancre-

Correspondence to: Dr Yasuhiro Kuramitsu, Department of Biochemistry and Functional Proteomics, Yamaguchi University Graduate School of Medicine, 1-1-1 Minami-Kogushi, Ube, Yamaguchi 755-8505, Japan

E-mail: climates@yamaguchi-u.ac.jp

Abbreviations: PC, pancreatic cancer; 2-DE, two-dimensional gel electrophoresis; LC-MS/MS, liquid chromatography-tandem mass spectrometry

Key words: two-dimensional gel electrophoresis, liquid chromatography-tandem mass spectrometry, pancreatic cancer, vinculin atic cancer and to clarify the biological characteristics of rapid aggressiveness of PC.

In recent years, proteomics has been widely applied to the identification of candidate biomarkers and therapeutic targets in various cancers (2-5). Two-dimensional gel electrophoresis (2-DE) and liquid chromatography-tandem mass spectrometry (LC-MS/MS) are the major proteomics techniques, which are utilized in analyzing proteins comprehensively.

The proteomics technology is an ideal option for finding biomarkers and therapeutic targets in cancer. By applying 2-DE and LC-MS/MS combined with western blotting, we found six differentially expressed proteins between pancreatic cancerous and non-cancerous tissues, and among them vinculin was identified as a potential biomarker for PC diagnosis or prognosis.

\section{Materials and methods}

Pancreatic tissues and sample preparation. Thirty pairs of non-cancerous and cancerous pancreatic tissues were obtained from 30 patients (Table I) who underwent resection of pancreas with diagnosis of pancreatic cancer at the Department of Surgery II, Yamaguchi University Hospital.

None of the patients received any preoperative therapy. Written informed consent was obtained from all patients before surgery. Tissues were obtained immediately after surgery and stored at $-80^{\circ} \mathrm{C}$ until use. The study protocol was approved by the Institutional Review Board for Human Use of the Yamaguchi University School of Medicine. The tissues were homogenized in lysis buffer (1\% NP-40, $1 \mathrm{mM}$ sodium vanadate, $1 \mathrm{mM}$ PMSF, $10 \mathrm{mM} \mathrm{NaF}, 10 \mathrm{mM}$ EDTA, $50 \mathrm{mM}$ Tris, $165 \mathrm{mM} \mathrm{NaCl}, 10 \mu \mathrm{g} / \mathrm{ml}$ leupeptin, and $10 \mu \mathrm{g} / \mathrm{ml}$ aprotinin) on ice (5). Suspensions were incubated for $2 \mathrm{~h}$ at $4^{\circ} \mathrm{C}$, and the supernatants were stored at $-80^{\circ} \mathrm{C}$ until they were used as samples. Ten pairs of samples were used for 2-DE, and twenty pairs for western blotting.

Two-dimensional gel electrophoresis (2-DE). As the first dimension, isoelectric focusing (IEF) was conducted in an IPGphor 3 IEF unit (GE Healthcare, Buckinghamshire, UK) on 11-cm and $\mathrm{pH}$ 3-10 linear gradient IPG strips (Bio-Rad, Hercules, CA, USA) at $50 \mu \mathrm{A} /$ strip. Protein $(80 \mu \mathrm{g})$ was used 
Table I. Clinicopathological parameters of patients with pancreatic cancer.

\begin{tabular}{|c|c|c|c|c|}
\hline No. & Age & Gender & TNM stage & Tumor grade \\
\hline $1^{\mathrm{a}}$ & 79 & Male & III & Moderately differentiated \\
\hline $2^{\mathrm{a}}$ & 67 & Male & III & Moderately differentiated \\
\hline $3^{\mathrm{a}}$ & 54 & Male & III & Moderately differentiated \\
\hline $4^{\mathrm{a}}$ & 75 & Male & $\mathrm{IVb}$ & Poorly differentiated \\
\hline $5^{\mathrm{a}}$ & 71 & Female & III & Well differentiated \\
\hline $6^{\mathrm{a}}$ & 58 & Male & $\mathrm{IVb}$ & Mucinous carcinoma \\
\hline $7^{\mathrm{a}}$ & 70 & Female & III & Moderately differentiated \\
\hline $8^{\mathrm{a}}$ & 64 & Male & III & Moderately differentiated \\
\hline $9^{\mathrm{a}}$ & 61 & Male & IVa & Moderately differentiated \\
\hline $10^{\mathrm{a}}$ & 51 & Female & II & Moderately differentiated \\
\hline 11 & 67 & Male & IVa & Well differentiated \\
\hline 12 & 60 & Female & III & Moderately differentiated \\
\hline 13 & 48 & Female & IVa & Moderately differentiated \\
\hline 14 & 73 & Male & IVa & Moderately differentiated \\
\hline 15 & 54 & Male & IVa & Moderately differentiated \\
\hline 16 & 57 & Male & $\mathrm{IVb}$ & Moderately differentiated \\
\hline 17 & 54 & Male & III & Moderately differentiated \\
\hline 18 & 74 & Female & IVa & Poorly differentiated \\
\hline 19 & 72 & Male & III & Moderately differentiated \\
\hline 20 & 72 & Male & IVa & Well differentiated \\
\hline 21 & 76 & Female & IVa & Moderately differentiated \\
\hline 22 & 73 & Female & III & Papillary carcinoma \\
\hline 23 & 53 & Male & $\mathrm{IVb}$ & Well differentiated \\
\hline 24 & 69 & Female & III & Moderately differentiated \\
\hline 25 & 79 & Male & $\mathrm{IVb}$ & Mucinous carcinoma \\
\hline 26 & 34 & Male & $\mathrm{IVb}$ & Acinor carcinoma \\
\hline 27 & 71 & Female & III & Moderately differentiated \\
\hline 28 & 67 & Female & IVa & Moderately differentiated \\
\hline 29 & 68 & Male & III & Moderately differentiated \\
\hline 30 & 60 & Male & $\mathrm{IVb}$ & Moderately differentiated \\
\hline
\end{tabular}

a indicates samples were used in 2-DE analysis.

for each 2-DE. Samples were mixed with $200 \mu 1$ of rehydration buffer [ $8 \mathrm{M}$ urea, $2 \%$ CHAPS, $0.01 \%$ bromophenol blue, $1.2 \%$ Destreak reagent (GE Healthcare)] and $0.5 \%$ IPG buffer, and loaded in the IPGphor strip holder. The strips were then focused by the following program: rehydration for $10 \mathrm{~h}$ (no voltage); 0-500 V for $4 \mathrm{~h}$; 500-1,000 $\mathrm{V}$ for $1 \mathrm{~h} ; 1,000-8,000 \mathrm{~V}$ for $4 \mathrm{~h} ; 8,000 \mathrm{~V}$ for $20 \mathrm{~min}$; and the final phase of $500 \mathrm{~V}$ from 20,000-30,000 Vh (6). After IEF, sodium dodecyl sulfate-polyacrylamide gel electrophoresis (SDS-PAGE) was performed on a precast polyacrylamide gel with a linear concentration gradient of $5-20 \%$ (Bio-Rad) (7). The IPG strips were first equilibrated in equilibration buffer 1 (6 M urea, $0.5 \mathrm{M}$ Tris-HCl, pH 8.8, 30\% glycerol, 2\% SDS, 2\% 2-ME) for $10 \mathrm{~min}$, and further in equilibration buffer 2 (6 M urea, $0.5 \mathrm{M}$ Tris- $\mathrm{HCl}, \mathrm{pH} 8.8,30 \%$ glycerol, 2\% SDS, $2.5 \%$ iodoacetamide) for $10 \mathrm{~min}$. The IPG strips were then transferred onto the gels, which were run at $200 \mathrm{~V}$ (8). Each sample was replicated three times to ensure protein pattern reproducibility.
Fluorescence staining. The SDS-PAGE gels were fixed with $40 \%$ ethanol and $10 \%$ acetic acid for $2.5 \mathrm{~h}$. The gels were then treated with a fluorescent gel staining, Flamingo ${ }^{\mathrm{TM}}$ Fluorescent Gel Stain (Bio-Rad), for 18 h (9). The stained gels were washed with Milli-Q water 3 times, for 5 min each. These experimental procedures were carried out on a shaker.

Image analysis and spot picking. The gels were scanned by using the ProXpress 2-D Proteomic Imaging System (PerkinElmer, Waltham, MA, USA) and then analyzed by using the Progenesis SameSpots software (Nonlinear Dynamics, Newcastle, UK) following the user manual. After image analysis, the gels were stained with See Pico $^{\text {TM }}$ (Benebiosis Co., Ltd., Seoul, Korea) overnight (10). The selected protein spots that displayed different intensities were cut from the gels and subjected to mass spectrometry (MS) analysis.

In-gel digestion. The gel pieces were destained by rinsing three times in $60 \%$ methanol, $0.05 \mathrm{M}$ ammonium bicarbonate, 
Table II. Upregulated proteins in pancreatic cancerous tissues.

\begin{tabular}{lcccccl}
\hline Spot & Accession no. ${ }^{\mathrm{a}}$ & $\mathrm{pI}^{\mathrm{b}}$ & $\mathrm{Mr}(\mathrm{Da})^{\mathrm{b}}$ & Spot intensity ratio & Frequency & Protein \\
\hline 1 & $\mathrm{P} 27797$ & 4.29 & 48141.8 & 2.10 & $9 / 10$ & Calreticulin \\
2 & $\mathrm{P} 48637$ & 5.67 & 52385.1 & 1.50 & $7 / 10$ & Glutathione synthetase \\
3 & $\mathrm{P} 16949$ & 5.76 & 17302.6 & 1.50 & $5 / 10$ & Stathmin \\
4 & $\mathrm{P} 18206$ & 5.50 & 123800.0 & 1.50 & $8 / 10$ & Vinculin \\
5 & $\mathrm{P} 06733$ & 7.01 & 47169.2 & 1.60 & $9 / 10$ & $\alpha$-enolase \\
6 & $\mathrm{P} 04406$ & 8.57 & 6053.4 & 1.70 & $7 / 10$ & Glyceraldehyde \\
& & & & & & 3-phosphate dehydrogenase
\end{tabular}

${ }^{\mathrm{a}}$ Accession number derived from the protein database. ${ }^{\mathrm{b}}$ Theoretical $\mathrm{pI}$ and molecular weight (Da) from the protein database.

and $5 \mathrm{mM}$ DTT for $15 \mathrm{~min}$. The sample in the gel piece was reduced twice in $50 \%$ methanol, $0.05 \mathrm{M}$ ammonium bicarbonate, and $5 \mathrm{mM}$ DTT for $10 \mathrm{~min}$. The gel pieces were dehydrated twice in $100 \%$ acetonitrile (ACN) for $30 \mathrm{~min}$. Enzyme digestion was carried out with an in-gel digestion reagent containing $10 \mu \mathrm{g} / \mathrm{ml}$ sequencing-grade-modified trypsin (Promega Corporation, Madison, WI, USA) in $30 \%$ ACN, $0.05 \mathrm{M}$ ammonium bicarbonate, and $5 \mathrm{mM}$ DTT at $30^{\circ} \mathrm{C}$ for $16 \mathrm{~h}$. The samples were lyophilized overnight with the use of Labconco Lyph-lock 1L Model 77400 (Labconco, Kansas, MO, USA).

LC-MS/MS analysis. The lyophilized samples were dissolved in $15 \mu \mathrm{l}$ of $0.1 \%$ formic acid, and then analyzed by using the LC-MS/MS system. Peptide sequencing of identified protein spots was carried out by using LC-MS/MS with a Spectrum Mill MS Proteomics Workbench (Agilent Technologies, Palo Alto, CA, USA). Fifteen microliters of each sample was injected and placed into separated columns (Zorbax 300SB-C18, $75 \mu \mathrm{m}, 150 \mathrm{~mm}$, Agilent Technologies). The Agilent 1100 capillary pump was operated in the following conditions: solvent $\mathrm{A}, 0.1 \%$ formic acid; solvent $\mathrm{B}, \mathrm{ACN}$ in $0.1 \%$ formic acid; column flow, $0.3 \mu \mathrm{l} / \mathrm{min}$ for primary flow, otherwise $300 \mu \mathrm{l} / \mathrm{min}$; gradient, $0-5 \mathrm{~min} 2 \% \mathrm{~B}$ and $60 \mathrm{~min}$ $60 \% \mathrm{~B}$; stop time: $60 \mathrm{~min}$. Proteins were identified in the Agilent Spectrum Mill MS Proteomics Workbench against the Swiss-Prot protein database search engine (http:// kr.expasy.org/sprot/) and MASCOT MS/MS Ions Search engine (http://www.matrixscience.com/search_form_select. $\mathrm{html}$ ). Standards for induction of candidate proteins were set as follows: filter by protein score $>10.0$, and filter peptide by score $>8$ (percent scored peak intensity).

Western blotting. The samples were separated by electrophoresis with SDS-PAGE gels and then transferred onto PVDF membranes at $90 \mathrm{~mA}$ for $78 \mathrm{~min}$. The membranes were blocked overnight with TBS containing $5 \%$ milk at $4{ }^{\circ} \mathrm{C}$ (11). They were incubated with the primary antibody against vinculin (anti-vinculin mouse monoclonal antibody, Sigma, St. Louis, MO, USA; 1:10,000), $\alpha$-enolase (anti-enolase goat polyclonal antibody, Santa Cruz Biotechnology, Inc., Santa Cruz, CA; 1:1,000) and actin (anti-actin goat polyclonal antibody, Santa Cruz Biotechnology, Inc.; 1:200). The
A

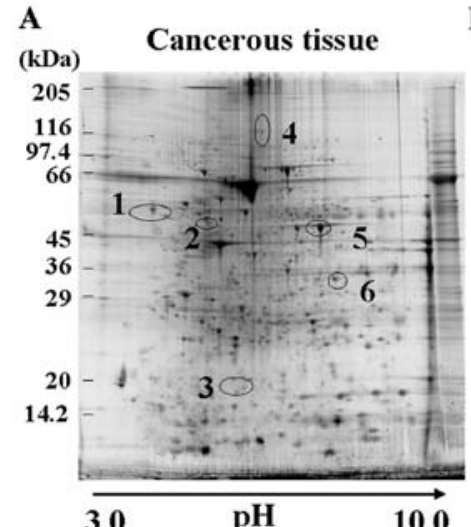

B Non-cancerous tissue

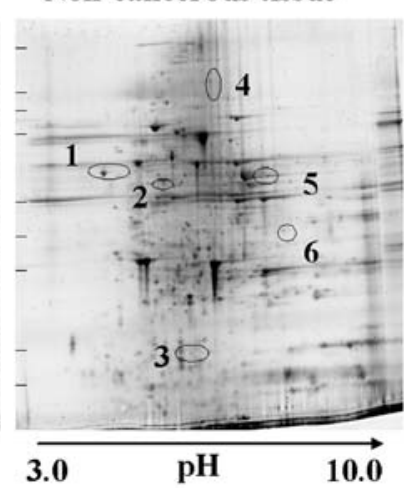

Figure 1. Two-dimensional gel electrophoresis images of pancreatic cancerous and non-cancerous tissues stained with Flamingo ${ }^{\mathrm{TM}}$ fluorescent gel stain. Proteins were separated on $\mathrm{pH}$ 3-10 linear, immobilized $\mathrm{pH}$ gradient strips followed by 5-20\% SDS-PAGE. Six spots showed enhanced intensity on gels of cancerous tissues (A) compared to non-cancerous tissues (B). They were numbered as spots 1-6

membranes were incubated with the secondary antibody conjugated with horseradish peroxidase $(1: 10,000)$ for $1 \mathrm{~h}$ at room temperature after washing three times with TBS containing Tween-20 and once with TBS. The membranes were treated with the ImmunoStar ${ }^{\circledR}$ LD chemiluminescent reagent (Wako Pure Chemical Industries Ltd., Osaka, Japan), and protein spots were detected by using the Image Reader LAS-1000 Pro (Fujifilm Corporation, Tokyo, Japan).

\section{Results}

Detection of protein spots in pancreatic cancerous and non-cancerous tissues on 2-DE gels. 2-DE gels were treated with a fluorescent gel stain, and then differences in the spot intensities between the tissues from pancreatic cancer and non-cancerous were analyzed and quantified by using the Progenesis SameSpots software. The results are summarized in Table II. At least 260 protein spots were matched on each 2-DE gel. Six upregulated spots (spots 1-6) were displayed on 2-DE gel with cancerous tissues at $>1.5$-fold higher intensity (Fig. 1). The protein expression levels were elevated significantly $(\mathrm{P}<0.05)$ in cancerous tissues when compared to paired non-cancerous tissues (Fig. 2). 

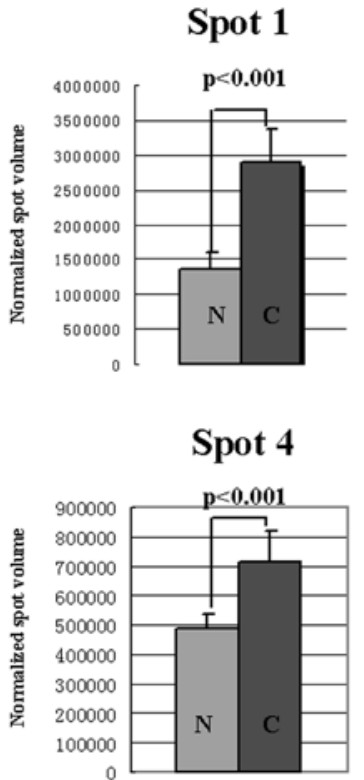

Spot 2

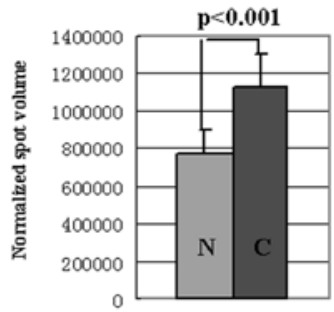

Spot 5

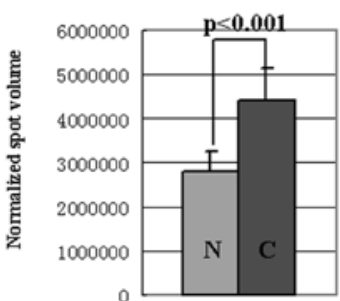

Spot 3

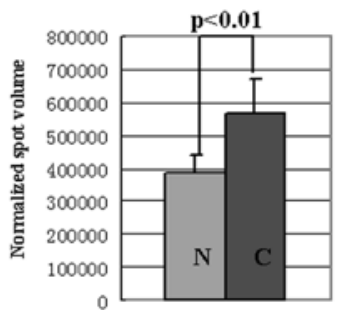

Spot 6

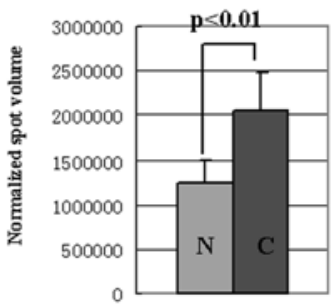

Figure 2. Enhanced protein expressions of carlreticulin (spot 1), glutathione synthetase (spot 2), stathmin (spot 3), vinculin (spot 4), $\alpha$-enolase (spot 5) and glyceraldehyde-3-phosphate dehydrogenase (spot 6) in pancreatic cancerous tissues. The graphs show the normalized intensity of each spot in cancerous (C) compared to non-cancerous $(\mathrm{N})$ tissues $(\mathrm{n}=30, \mathrm{P}<0.05)$. Spot numbers are same as in Fig. 1.

A

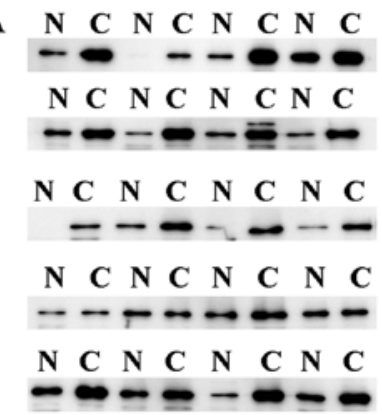

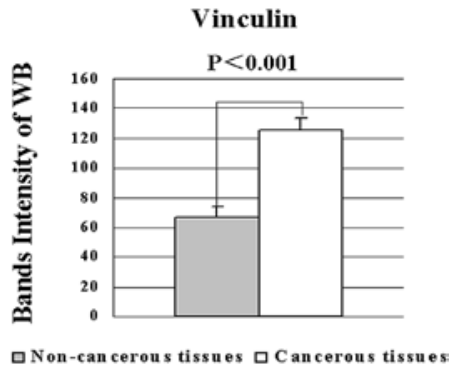

B

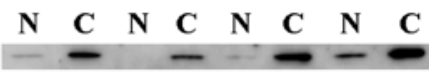

C

\begin{tabular}{lllllllll}
$\mathbf{N}$ & $\mathbf{C}$ & $\mathbf{N}$ & $\mathbf{C}$ & $\mathbf{N}$ & $\mathbf{C}$ & $\mathbf{N}$ & $\mathbf{C}$ \\
\hline
\end{tabular}

Figure 3. Western-blot analyses of vinculin and $\alpha$-enolase in pancreatic cancerous and non-cancerous tissues. (A) Tissues from 20 patients with pancreatic cancerous and paired non-cancerous tissues were used for western blotting with anti-vinculin antibody. The expression of vinculin was increased in pancreatic cancerous tissues $(80 \%)$. Intensities of the bands were compared between cancerous and non-cancerous tissues by Student's t-test $(n=20, P<0.001)$. The relative standard errors (SE) of cancerous and non-cancerous tissue samples were 8.438 and 7.695, respectively. Expressions of $\alpha$-enolase (B) and actin (C) were confirmed by western blotting respectively; the intensity of each band of $\alpha$-enolase was stronger in cancerous tissues than in non-cancerous tissues. $\mathrm{N}$, non-cancerous tissues; $\mathrm{C}$, cancerous tissues.
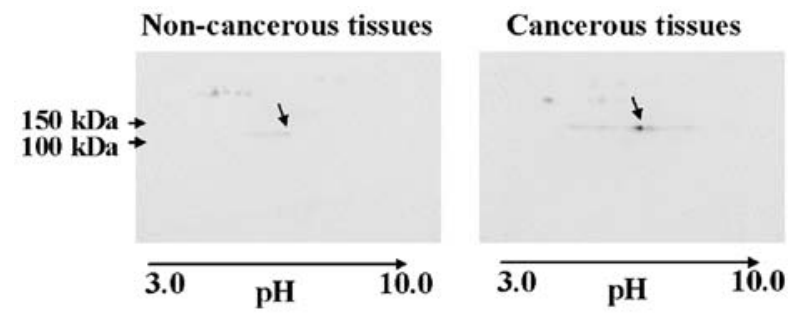

Figure 4. Two-dimensional (2-D) western blotting of vinculin in pancreatic cancerous tissues. Two-dimensional western blotting was performed on a pair of samples on $\mathrm{pH}$ 3-10 linear, which confirmed the locations of vinculin on PVDF membranes. The upregulated spot of vinculin was observed in cancerous tissue, compared to non-cancerous tissues.
Identification of proteins by $L C-M S / M S$. The samples were digested with trypsin and then analyzed by using LC-MS/MS system, which identified the six upregulated protein spots as calreticulin (spot 1), glutathione synthetase (spot 2), stathmin (spot 3), vinculin (spot 4), $\alpha$-enolase (spot 5) and glyceraldehyde-3-phosphate dehydrogenase (spot 6). The spot numbers are the same as those in Fig. 1. MS/MS data of these proteins are summarized in Table II.

Western blot analysis of vinculin and $\alpha$-enolase. There are still no reports regarding overexpression of vinculin in PC and its importance for cell adhesion and migration $(12,13)$. 
Twenty pairs of pancreatic cancerous and non-cancerous tissues were analyzed by western blotting with anti-vinculin antibody, and the different intensities of the bands between cancerous and non-cancerous tissues were analyzed by the Student's t-test (Fig. 3A). The mean intensities of the bands of cancerous and non-cancerous tissue samples were 125.2 and 66.4, respectively (Fig. 3A). Four pairs of cancerous and non-cancerous tissues were used for western blotting, to demonstrate the upregulation of $\alpha$-enolase (14) as a positive control in cancerous tissues, compared to non-cancerous tissues (Fig. 3B). The appearance of vinculin on the 2-DE gels was located by 2-D western blotting (Fig. 4).

\section{Discussion}

We identified six upregulated proteins, calreticulin, glutathione synthetase, stathmin, vinculin, $\alpha$-enolase and glyceraldehyde-3-phosphate dehydrogenase, in pancreatic cancerous tissues, compared to non-cancerous tissues. In this study, we reported only on those increased in cancerous tissues because many of the decreased proteins may have been replaced by stromal cells. To the best of our knowledge, this is the first report suggesting that vinculin is a candidate biomarker of PC.

Vinculin is a highly conserved intracellular protein $(\sim 123.8 \mathrm{kDa})$ with an important role in the regulation of cell adhesion and migration $(12,13)$. Bakolitsa et al have explained how vinculin regulates cell adhesion by their detailed protein structural analysis (15). Highly metastatic cells have been reported to lack vinculin expression $(16,17)$. Vinculin inhibits cell metastasis when transfected back into vinculin-null cells (17). Evidence reveals that apoptosis is related to cell motility $(18,19)$, and that vinculin regulates cell apoptosis and motility via controlling the ERK pathway (18).

Paradoxically, our study demonstrated that vinculin, which usually behaves as a potent inhibitor to the survival and motility of cells (16-18), was significantly overexpressed in pancreatic cancerous tissues. Our findings indicate that vinculin could be a useful biomarker of PC for its high specificity. Vinculin is well characterized by its intracellular connecting component within adhesion complexes (16), but its functions remain unclear. A new report suggests that vinculin is a main driver gene of the 10q22 amplification in 10q22-amplified prostate carcinomas and that overexpression of vinculin may play an enhancing role in tumor cell proliferation during prostate cancer progression (20). This may be explained by the alternative splicing of vinculin gene, resulting in the alteration of the vinculin function during prostate carcinogenesis (21). Further studies are required to clarify whether vinculin overexpression contributes to PC progression by enhancing tumor cell proliferation, and to elucidate vinculin's action in PC. Additional studies must be conducted in order to identify post-transcriptional modifications of vinculin in PC. Our data sheds light on a new facet of vinculin; its function in PC progression.

A previous report demonstrated that vinculin is related to tumor-suppressing properties (22). However, our findings revealed a different property of vinculin in PC and suggest that vinculin may play a significant role in the diagnosis or prognosis of PC.

\section{Acknowledgements}

We thank Ms. Yanome for proofreading the manuscript. This study was supported in part by a Grant-in-Aid from the Ministry of Health, Labor and Welfare of Japan (no. H20-Bio005 to K.N.).

\section{References}

1. Jemal A, Siegel R, Ward E, Hao Y, Xu J and Thun MJ: Cancer statistics, 2009. CA Cancer J Clin 59: 225-249, 2009.

2. Kuramitsu Y, Miyamoto H, Tanaka T, Zhang X, Fujimoto M, Ueda K, Tanaka T, Hamano K and Nakamura K: Proteomic differential display analysis identified upregulated astrocytic phosphoprotein PEA-15 in human malignant pleural mesothelioma cell lines. Proteomics 9: 5078-5089, 2009.

3. Luk JM, Lam CT, Siu AF, Lam BY, Ng IO, Hu MY, Che CM and Fan ST: Proteomic profiling of hepatocellular carcinoma in Chinese cohort reveals heat-shock proteins (Hsp27, Hsp70, GRP78) up-regulation and their associated prognostic values. Proteomics 6: 1049-1057, 2006.

4. Roth U, Razawi H, Hommer J, Engelmann K, Schwientek T, Müller S, Baldus SE, Patsos G, Corfield AP, Paraskeva C and Hanisch FG: Differential expression proteomics of human colorectal cancer based on a syngeneic cellular model for the progression of adenoma to carcinoma. Proteomics 10: 194-202, 2010.

5. Kuramitsu Y, Harada T, Takashima M, Yokoyama Y, Hidaka I Iizuka N, Toda T, Fujimoto M, Zhang X, Sakaida I, et al: Increased expression and phosphorylation of liver glutamine synthetase in well-differentiated hepatocellular carcinoma tissues from patients infected with hepatitis C virus. Electrophoresis 27: 1651-1658, 2006.

6. Tanaka T, Kuramitsu Y, Fujimoto M, Naito S, Oka M and Nakamura K: Downregulation of two isoforms of ubiquitin carboxyl-terminal hydrolase isozyme L1 correlates with high metastatic potentials of human SN12C renal cell carcinoma cell clones. Electrophoresis 29: 2651-2659, 2008.

7. Kuramitsu Y, Hayashi E, Okada F, Tanaka T, Zhang X, Ueyama Y and Nakamura K: Proteomic analysis for nuclear proteins related to tumour malignant progression: a comparative proteomic study between malignant progressive cells and regressive cells. Anticancer Res 30: 2093-2099, 2010.

8. Kuramitsu Y, Baron B, Yoshino S, Zhang X, Tanaka T, Yashiro M, Hirakawa K, Oka M and Nakamura K: Proteomic differential display analysis shows up-regulation of 14-3-3 protein sigma in human scirrhous-type gastric carcinoma cells. Anticancer Res 30: 4459-4465, 2010.

9. Kuramitsu Y, Taba K, Ryozawa S, Yoshida K, Zhang X, Tanaka T, Maehara S, Maehara Y, Sakaida I and Nakamura K: Identification of up- and down-regulated proteins in gemcitabine-resistant pancreatic cancer cells using two-dimensional gel electrophoresis and mass spectrometry. Anticancer Res 30: 3367-3372, 2010.

10. Kuramitsu Y, Hayashi E, Okada F, Zhang X, Tanaka T, Ueyama Y and Nakamura K: Staining with highly sensitive Coomassie brilliant blue SeePico ${ }^{\mathrm{TM}}$ stain after Flamingo ${ }^{\mathrm{TM}}$ fluorescent gel stain is useful for cancer proteomic analysis by means of twodimensional gel electrophoresis. Anticancer Res 30: 4001-4005, 2010.

11. Mori-Iwamoto S, Kuramitsu Y, Ryozawa S, Mikuria K, Fujimoto M, Maehara S, Maehara Y, Okita K, Nakamura K and Sakaida I: Proteomics finding heat shock protein 27 as a biomarker for resistance of pancreatic cancer cells to gemcitabine. Int J Oncol 31: 1345-1350, 2007.

12. Volberg T, Geiger B, Kam Z, Pankov R, Simcha I, Sabanay H, Coll JL, Adamson E and Ben-Ze'ev A: Focal adhesion formation by $\mathrm{F} 9$ embryonal carcinoma cells after vinculin gene disruption. J Cell Sci 108: 2253-2260, 1995.

13. Xu W, Baribault H and Adamson ED: Vinculin knockout results in heart and brain defects during embryonic development. Development 125: 327-337, 1998.

14. Mikuriya K, Kuramitsu Y, Ryozawa S, Fujimoto M, Mori S, Oka M, Hamano K, Okita K, Sakaida I and Nakamura K: Expression of glycolytic enzymes is increased in pancreatic cancerous tissues as evidenced by proteomic profiling by twodimensional electrophoresis and liquid chromatography-mass spectrometry/mass spectrometry. Int J Oncol 30: 849-855, 2007. 
15. Bakolitsa C, Cohen DM, Bankston LA, Bobkov AA, Cadwell GW, Jennings L, Critchley DR, Craig SW and Liddington RC: Structural basis for vinculin activation at sites of cell adhesion. Nature 430: 583-586, 2004.

16. Rüdiger M: Vinculin and alpha-catenin: shared and unique functions in adherens junctions. Bioessays 20: 733-740, 1998.

17. Rodríguez Fernández JL, Geiger B, Salomon D, Sabanay I, Zöller M and Ben-Ze'ev A: Suppression of tumorigenicity in transformed cells after transfection with vinculin cDNA. J Cell Biol 119: 427-438, 1992.

18. Subauste MC, Pertz O, Adamson ED, Turner CE, Junger S and Hahn KM: Vinculin modulation of paxillin-FAK interactions regulates ERK to control survival and motility. J Cell Biol 165: 371-381, 2004
19. Frisch SM and Francis H: Disruption of epithelial cell-matrix interactions induces apoptosis. J Cell Biol 124: 619-626, 1994.

20. Ruiz C, Holz DR, Oeggerli M, Schneider S, Gonzales IM, Kiefer JM, Zellweger T, Bachmann A, Koivisto PA, Helin HJ, et al: Amplification and overexpression of vinculin are associated with increased tumour cell proliferation and progression in advanced prostate cancer. J Pathol 223: 543-552, 2011.

21. Thorsen K, Sørensen KD, Brems-Eskildsen AS, Modin C, Gaustadnes M, Hein AM, Kruhøffer M, Laurberg S, Borre M, Wang K, et al: Alternative splicing in colon, bladder, and prostate cancer identified by exon array analysis. Mol Cell Proteomics 7: 1214-1224, 2008.

22. Ziegler WH, Liddington RC and Critchley DR: The structure and regulation of vinculin. Trends Cell Biol 16: 453-460, 2006. 